\title{
Rapid Microwave-accelerated Multi-step Synthesis of 2,6-di(naphthalene Thioureido Carbamino)Pyridine
}

\author{
Hairui Zhang ${ }^{1}$ and Guofu Zhang ${ }^{2}$, \\ 1. School of Electronic and Information Engineering, Lanzhou City University, Lanzhou 730070, China \\ 2. School of Chemistry and Environmental Engineering, Lanzhou City University, Lanzhou 730070, China
}

\begin{abstract}
A rapid and simple procedure for synthesis of 2,6-di(naphthalene thioureido carbamino)pyridine fluorescine anion acceptor by the reaction between pyridine-2,6-dicarbohydrazide obtained from 2,6-dimethylpyridine after three-step reaction and 1-naphthyl isothiocyanate is described, and all reactions could be carried out under microwave heating condition.
\end{abstract}

Key words: 2,6-di(naphthalene thioureido carbamino)pyridine, pyridine-2,6-dicarboxylic acid, dimethyl 2,6-pyridinedi- carboxylate, pyridine-2,6-dicarbohydrazide, microwave irradiation.

\section{Introduction}

Anion recognition and sensing have been developed into an important research subject to construct a variety of anion receptors that play important roles in biology, medicine, catalysis and the environment, developing hydrogen bonding force existing in anion receptor has recently been paid great attention by chemists [1]. Amine, amide, thiourea, pyrrole, and phenol are hydrogen bonding donators and applied widely in the designing and synthesis of anion acceptor. Owing to the relatively strong hydrogen bonding ability of thiourea and amide groups, a number of molecules possessing thiourea or amide groups have been designed as neutral receptors for various anions. For strong and selective binding, we have been interested in developing aminoacyl thiourea anion acceptor, which forms multi hydrogen bonding interaction with anions. The 2,6-di(naphthalene thioureido carbamino)pyridine is a fluorescine anion acceptor with two thiourea and amide groups. This paper describes the multi-step synthesis of 2,6-di(naphthalene thioureido carbamino)pyridine

Corresponding author: Hairui Zhang, Hairui Zhang, master, lecturer, research fields: resource management, grid and cloud computing. compound under microwave heating condition [2].

Microwave heating has been used for a wide variety of applications including the rapid synthesis of organic compounds and become a classic method in organic chemistry. There are a variety of methods for carrying out microwave assisted organic reactions using domestic or commercial ovens. Recently, we have reported the rapid and efficient synthesis of benzoyl phenylthiourea and phenylacetyl arylthiourea compounds under microwave irradiation [3]. The phenylacetyl arylthioureas can be obtained from the reaction of phenylacetyl chloride with first ammonium thiocyanate and then arylamines in a solid-liquid system with polyethylene glycol-400 as catalyst under microwave irradiation.

Using our methodology, the reaction is performed in an improved reflux commercial microwave oven. The oxidation reaction process is safe and smooth compared to sealed tube. As a starting point for the development of our microwave-mediated methodology, we initially studied the microwave promoted oxidation reaction of 2,6-dimethylpyridine by potassium permanganate in water. The direct esterification of pyridine-2,6-dicarboxylic acid with methanol catalyzed by sulfuric acid also takes place in excellent isolated yields under microwave heating 
condition. The experimental results showed that the microwave irradiation can shorten the reaction time dramatically, the yields of the products are often increased, a comparing with the original method [4]. On routine method basis using microwave technology, the pyridine-2,6-dicarbohydrazide and the target compound was prepared in excellent yields.

In conclusion, we have developed a reliable, efficient method for multi-step synthesis 2,6-di(naphthalene thioureido carbamino)pyridine fluorescine anion acceptor in excellent yields that involve the use of green media and microwave heating technology. Particularly valuable features of this methodology are superior from the point of view of yield, short reaction time, save energy, as well as an environmentally friendly synthesis than the reported methods. From a synthetic perspective, these results open new possibilities for exploiting the multi-step reaction under microwave irradiation conditions [5].

\section{Experimental}

The melting points were determined on a WRS-1 A digital melting point apparatus. IR spectra were measured for $\mathrm{KBr}$ discs using an Alpha Centauri FT-IR spectrophotometer. ${ }^{1} \mathrm{H}$ NMR spectra were recorded on a Mercury plus $400 \mathrm{MHz}$ spectrometer in DMSO- $_{6}$ with TMS as an internal standard. EI-MS were measured on an HP5988A mass spectrometer. Element analysis was performed on a Carlo-Erba 1106 microanalyzer.

Microwave irradiation is carried out with an improved reflux commercial microwave oven. A round-bottomed flask $(50-250 \mathrm{~mL})$ was placed inside the microwave cavity and a double-surface reflux condenser attached to this. The reaction process is safe and smooth.

\subsection{General Procedure for the Synthesis of Compound 2}

In a $250 \mathrm{~mL}$ round-bottomed flask were placed 2,6-dimethylpyridine (5.0 mmol), $\mathrm{KMnO}_{4}(22.5 \mathrm{mmol})$ and $20 \mathrm{~mL}$ water. The flask was put into microwave oven, then turned on microwave oven at $375 \mathrm{~W}$ for 30 $\mathrm{min}$. The reaction mixture was filtered without cooling down. The filter liquor cooling down in ice-water bath and acidifying with $3.0 \mathrm{~mL} \mathrm{H}_{2} \mathrm{SO}_{4}(70 \%)$ to afford the pyridine-2,6-dicarboxylic acid. The product was recrystallized from water to give the analytically pure sample. Yield: $86 \%$, mp. $231-232{ }^{\circ} \mathrm{C}$, IR ( $\mathrm{KBr}, v_{\max }$ $\left.\mathrm{cm}^{-1}\right): 3200(\mathrm{O}-\mathrm{H}), 1680(\mathrm{C}=\mathrm{O}), 1550(\mathrm{~N}=\mathrm{C}),{ }^{1} \mathrm{H}$ NMR (400 MHz, $\left.\mathrm{CDCl}_{3}, \delta, \mathrm{ppm}\right): 12.78(\mathrm{~s}, 2 \mathrm{H}$, $\left.\mathrm{CO}_{2} \mathrm{H}\right), 8.22$ (s, 3H, $\mathrm{PyH}$ ).

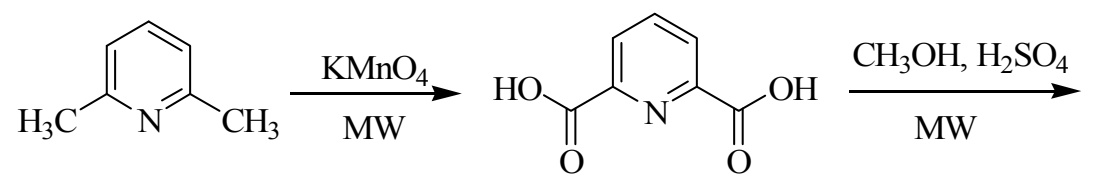

1

2<smiles>CCOC(=O)c1cccc(C(=O)OC)n1</smiles>

3

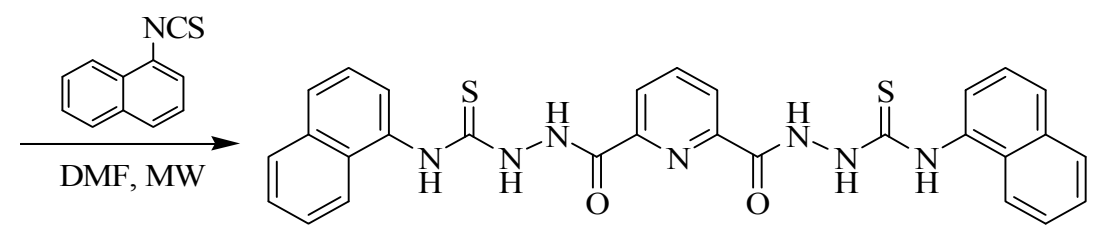

5

Scheme 1 


\subsection{General Procedure for the Synthesis of Compound 3}

The pyridine-2,6-dicarboxylic acid (10 mmol), methanol ( $25 \mathrm{mmol}), 30 \% \mathrm{H}_{2} \mathrm{SO}_{4}(2 \mathrm{~mL})$ were added in a bottle $(100 \mathrm{~mL})$, and irradiated at $375 \mathrm{~W}$ for 30 min in microwave oven. After cooling to room temperature, the crystal was filtered to give the analytically pure product. Yield: $95 \%$, mp. $122-123{ }^{\circ} \mathrm{C}$, IR $\left(\mathrm{KBr}, v_{\max } \mathrm{cm}^{-1}\right): 1742(\mathrm{C}=\mathrm{O}), 1571,1444(\mathrm{~N}=\mathrm{C})$, 1247(C-O). ${ }^{1} \mathrm{H}$ NMR(400 MHz, $\left.\mathrm{CDCl}_{3}, \delta, \mathrm{ppm}\right)$ : 8.20-8.30 (s, 3H, $\mathrm{PyH}), 4.04$ (s, 6H, $\mathrm{CH}_{3}$ ).

\subsection{General Procedure for the Synthesis of Compound 4}

In a $100 \mathrm{~mL}$ round-bottomed flask were placed dimethyl 2,6-pyridinedicarboxylate $(10 \mathrm{mmol})$, dehydrated alcohol $(20 \mathrm{~mL})$, hydrazine hydrate $(25$ $\mathrm{mmol}$ ), and irradiated at $225 \mathrm{~W}$ for $5 \mathrm{~min}$ in microwave oven. The mixture was filtered without cooling down, the filtter cake was washed by water and alcohol twice to give white product. Yield: $96 \%$, mp. $286-287{ }^{\circ} \mathrm{C}$, IR (KBr, $\left.v_{\max } \mathrm{cm}^{-1}\right): 3441(\mathrm{~N}-\mathrm{H})$, 3279 (CON-H), 3191 (C-H), 3019, 2952 (C-H), 1688 $(\mathrm{C}=\mathrm{O}), 1643(\mathrm{~N}=\mathrm{C}), 1518(\mathrm{C}=\mathrm{N}) .{ }^{1} \mathrm{H}$ NMR $(400 \mathrm{MHz}$, $\mathrm{CDCl}_{3}, \delta, \mathrm{ppm}$ ): 10.85 (s, 2H, CONH), 7.83 (s, 3H, $\mathrm{PyH})$, 4.02-4.14 (s, $\left.4 \mathrm{H}, \mathrm{NH}_{2}\right)$. Element analysis: C: 43.07; H: 4.05; N: 35.89; found C: 43.85, H4.05, N: 34.98.

\subsection{General Procedure for the Synthesis of Compound 5}

In a $50 \mathrm{~mL}$ round-bottomed flask were placed Pyridine-2,6-dicarbohydrazide (1 mmol), 1-naphthyl isothiocyanate $(2 \mathrm{mmol})$ and DMF $(5 \mathrm{~mL})$. The flask was put into microwave oven, then turned on microwave oven at $150 \mathrm{~W}$ for $10 \mathrm{~min}$. The reaction mixture was poured into a beaker which contained 200 $\mathrm{mL}$ water in ice-water bath. The white solid was filtered and washed by small amount of water, cold alcohol respectively, to give analytically pure product. Yield: 96\%, mp:176-177 ${ }^{\circ} \mathrm{C}$, IR $\left(\mathrm{KBr}, v_{\max } \mathrm{cm}^{-1}\right)$ : 3246 (N-H ), 3062 (C-H ), 2978 (C-H), 1689 (C=O),
$1653(\mathrm{~N}=\mathrm{C}), 1530(\mathrm{C}=\mathrm{C}), 1152(\mathrm{C}=\mathrm{S}) .{ }^{1} \mathrm{H}$ NMR $(400$ MHz, DMSO, $\delta$, ppm ): 11.26 (s, 2H, ArNHCS), 9.86 (s, 2H, NHCS), 9.80 (s, 2H, PyCONH), 8.28-7.15 (m, 17H, ArH). EI-MS (70 eV) m/z: $566\left(\mathrm{M}^{+}\right)$. Element analysis: C, 61.57, $\mathrm{H}, 4.10, \mathrm{~N}, 17.33$; found $\mathrm{C}, 61.23$, $\mathrm{H}, 4.15, \mathrm{~N}, 17.49$.

\section{Results and Discussion}

In conclusion, the authors get a novel compound which has side chain of dithiocarbonhydrazide. The result shows that the concentration of $\mathrm{N}_{2} \mathrm{H}_{4} \mathrm{H}_{2} \mathrm{O}$ and the rate of substrate are of little influence to rate of reaction, purity of product and yield of product. But to avoid the occurence of the side-reaction, the authors used excess $\mathrm{N}_{2} \mathrm{H}_{4} \mathrm{H}_{2} \mathrm{O}$ (twice amount), and reacted in alcohol. In the process of synthesizing the final product, the authors try different solvents, and we choose DMF at last because DMF is superior to others. The speed is good, and the phenomenon is obvious too. This yield is the highest when reacted at $150 \mathrm{~W}$ for $10 \mathrm{~min}$ in microwave oven while the mol rate of 2,6-pyridindicarboxhydrazide and 1-naphthylisothiocyanate is 1:2.

\section{References}

[1] Wei, L., Wu, Y., Wang, F., Meng, L., and He, Y. 2003. "Fluorescent Receptor Containing Diaminothiourea Branches Synthesis and Anion Recognition." Wuhan Univ. (Nat. Sci. Ed.) 49 (6): 709-12.

[2] Beer, P., and Gale, P. J. 2001. "Anion Recognition and Sensing: The State of the Art and Future Perspectives." Angew. Chem. Int. Ed. Engl. 40: 486-516.

[3] Zhang, G., Zhang, H., Ye,, H., and Zhang, Q. 2011. "The Microwave Synthesis of 2,6-pyridine Dicarboxylic Hydrazine." Journal of chemistry and Chemical Engineering 5 (11): 1041-5.

[4] Zhang, G., Zhang, Q., Zhang, H., Bai, L., Ye, H., and Liu, L. 2010. "The Synthesis of Pyridine 2,6-dicarboxylic Acid Using Microwave Irradiation." Journal of Chemistry and Chemical Engineering 4 (11): 60-4.

[5] Zhang, G., Zhang, Q., Ye, H., Liu, L., and Zang, L. 2010. "Synthesis of 2,6-pyridine Dimethyl Formate under Microwave Irradiation." Journal of Chemistry and Chemical Engineering 5 (3): 255-8. 